\title{
Radiological Evaluation of the Calcaneal Parameters in an Adult Nigerian Population
}

\author{
Authors \\ Giami Barinem, Udoaka A.I.
}

Department of Human Anatomy, University of Port Harcourt, Port Harcourt, Nigeria

\begin{abstract}
Axial relationships are the various interactions and connections among structures along an axis. The axial relationships of the calcaneus are necessary so as to evaluate certain parameters that would be useful in the diagnosis and treatment of calcaneal fractures. This study was performed to evaluate the normal reference range of the axial relationships of the Calcaneus in adult Nigerians, and to compare the results with published data of other populations. 302 normal lateral plain film radiographs of the ankle joint were sourced from the archives of various teaching hospitals in Nigeria, and Parameters namely; Gissane angle, Fowler-Philip angle, calcaneal pitch angle and total calcaneal angle were measured. Range for Gissane angle was 100-140 with mean of 116.53 + 8.03. 60-85 for Fowler-Philip angle with mean of $73.50 \pm 4.32 .10-30$ for calcaneal pitch angle with mean of 14.50+3.55.73-101 for Total calcaneal angle with mean of $88.00+2.60$; The axial angles of the calcaneus for the Nigerian population were different from the published data. These parameters would be useful in the diagnosis and treatment of calcaneal fractures in Nigeria.
\end{abstract}

Keywords: calcaneal parameters, calcaneal fracture, ankle joint, radiograph, Nigeria.

\section{INTRODUCTION}

Axial relationships are the various interactions and connections among structures along an axis. These relationships are very useful in evaluating certain parameters like the normal axial angles in the knee (1). These parameters are generally useful as they serve as reference values for the diagnosis and treatment of various clinical conditions.

The calcaneus is the largest of the tarsal bones and also the largest bone of the foot. It forms the heel pad ${ }^{(2)}$. In the calcaneus, an ossification center is developed during the 4-7th week of fetal development ${ }^{(3)}$. Its morphology is important for the rearfoot because it influences the static and dynamic aspects of walking ${ }^{(4)}$.The axial relationships of the calcaneus is necessary so as to evaluate certain parameters that would be useful in the diagnosis and treatment of calcaneal fractures, as calcaneal fractures account for $2 \%$ of all fractures and $60 \%$ of tarsal injuries ${ }^{(5)}$.

Axial angles of the calcaneus have been evaluated in other populations ${ }^{(6,7,8)}$. The studies carried out in these populations showed regional and ethnic variations hence, an evaluation of the axial relationships of the calcaneus is needed for the Nigerian population in other to establish a reference range that will be defending for the population. This study seeks to evaluate the 
Gissane angle, Fowler-philip angle, Calcaneal pitch angle and the total calcaneal angle for the Nigerian population. This will serve as a reference guide in Nigeria and therefore help in improving the standard of Calcaneal fracture treatment in Nigeria.

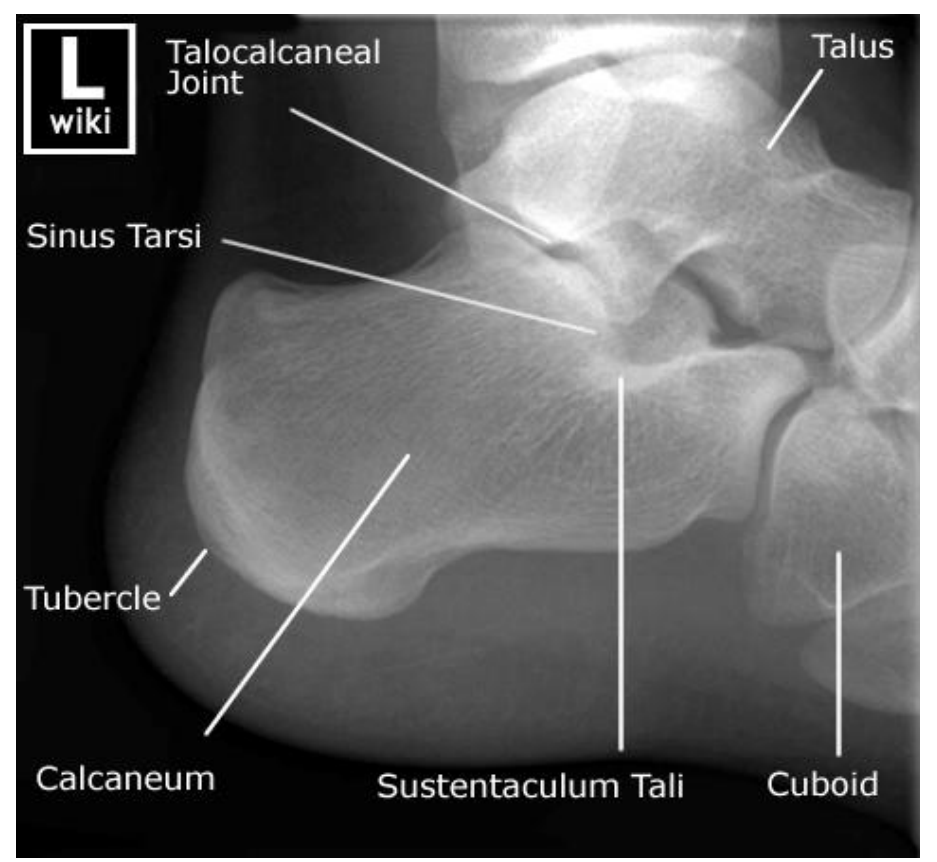

Fig1.1: Lateral radiograph of the normal calcaneus (Adapted from wiki.com)

The crucial angle of Gissane is seen directly inferior to the lateral process of the talus, formed by a line drawn along the posterior facet of the calcaneus and a line drawn from the anterior process to the sulcus calcaneus ${ }^{(9)}$. It is also widely accepted that a normal crucial angle of Gissane is 100 to 130 degrees ${ }^{(10)}$. Different ranges of values exist for different populations as show $\mathrm{n}$ by studies in those populations. In the Saudi population, the Gissane angle is 96-152 degrees (11). In 2009, a range of 100-133 degrees was evaluated as the Gissane angle in the Turkish population ${ }^{(6)}$. The Fowler-Philip angle represents the posterior radiologic morphology of the calcaneus with normal range believed to be 44-69 degrees ${ }^{(12,13,14)}$. A fowler Philip angle greater than $75^{\circ}$ is considered abnormal and patients/subjects with this greater than normal value are more likely to have Haglund's disease ${ }^{(15)}$. A range of $46-71^{\circ}$ was considered normal for the Hong kong population ${ }^{(16)}$. The Calcaneal pitch angle is an angle that describes the calcaneal inclination that is decreased in flatfoot ${ }^{(17)}$. The Calcaneal Pitch angle has been shown to be useful in determining flatfoot and normal foot $(18,19)$. Angular measurements of 15-20 degrees were considered normal ${ }^{(19,20)}, 10-30^{\circ}$ is also normal . In the Saudi population, a range of 20-30 degrees were considered normal (21). In the Hong kong population, a range of $12-28^{\circ}$ were considered normal ${ }^{(16)}$. The total Calcaneal angle is defined by some authors as the sum of the Fowler-Philip angle and the Calcaneal pitch angle. They argue that this definition is more consistent and better reflects the general morphology of the calcaneus ${ }^{(20,22)}$. Values of 64.8-89.8 degrees were considered normal ${ }^{(20)}$. A range of $61-109^{\circ}$ was considered normal for the Hong kong population (16). A total calcaneal angle greater than $90^{\circ}$ is considered abnormal and such patients would be more likely to develop talalgia, Achilles tendinitis and other complications.

\section{MATERIALS AND METHOD}

A total of three hundred and two (302) of which one hundred and fifty two (152) were males and one hundred and fifty (150) were females. These normal plain film radiographs of the ankle joint were sourced from the archives of five (5) teaching hospitals all in Nigeria. Radiographs showing traumatic, infective or neoplastic bony abnormalities or not displaying a full lateral view of the calcaneus were not included in the study, only those radiographs of adult patients reported to be normal by a radiologist were used. The procedure for taking measurements as put forward by Shoukry et al., 2012 was used in the measurement of the angles as follows;

Anatomical landmarks were determined on the radiographs.

Reference lines were drawn on the radiograph using a HB pencil and a measuring rule in millimeters.

A compass in place of a hand held geniometer was used to take measurements. 


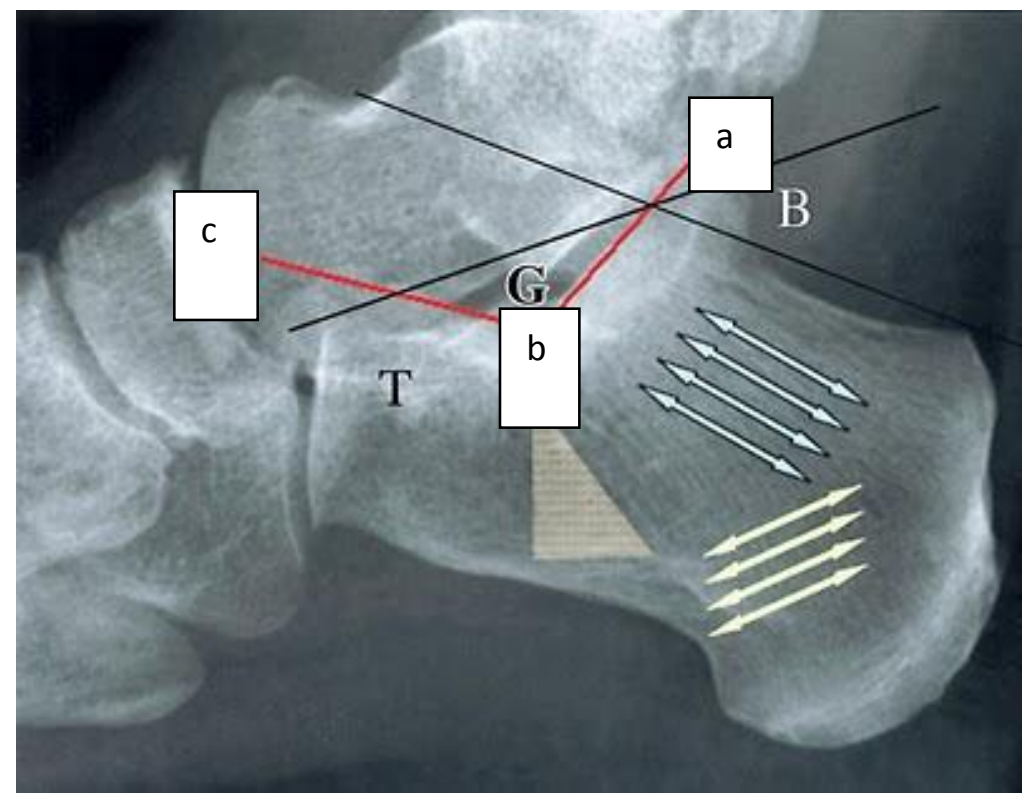

Line AB - line running along the lateral border of thecalcaneus.

Line BC - running anteriorly to the beak $o$ the calcaneus.

Fig 2: Lateral radiograph of the ankle joint showing the Gissane angle. (Adapted from ourorthopaedics blogspot.com)

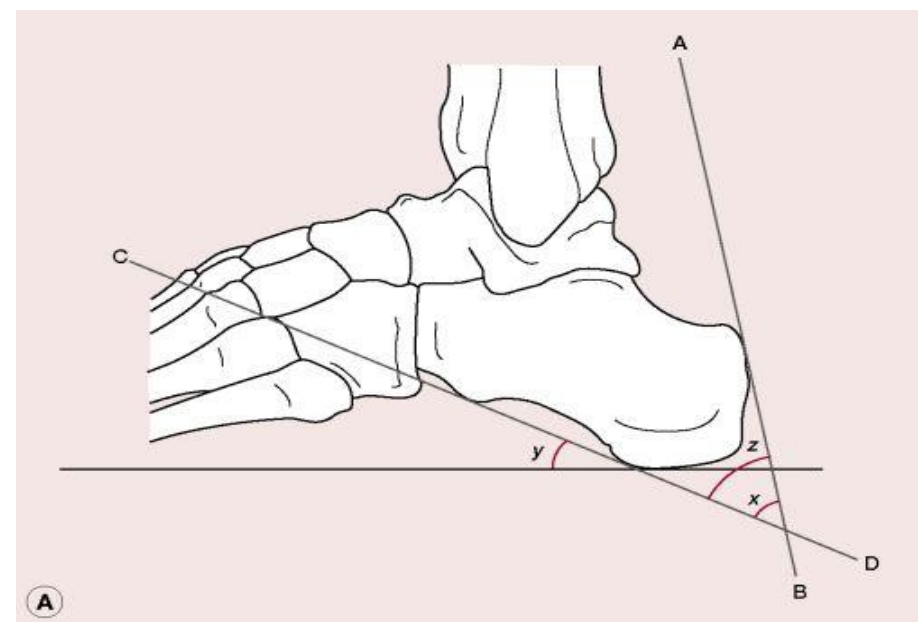

Line $\mathrm{AB}$ - line tangential to the posterior tuberosity

Line $\mathrm{CD}$ - line tangential to the plantar tuberosity

Angle $\mathrm{x}$ - Fowler-Philips angle

Angle y - Calcaneal pitch angle

Angle z - Total calcaneal angle

Fig 3: Diagram showing the posterior calcaneal angle or Fowler-Philip angle, Calcaneal pitch angle and total calcaneal angle. (Adapted from medical.dictionary.the free dictionary.com)

The Angle of Gissane, or "Critical Angle", is the angle formed by the downward and upward slopes of the calcaneus. $\mathrm{A}$ line $\mathrm{AB}$ is drawn along the lateral border of posterior facet and the intersection with line BC running anteriorly to the beak of the calcaneus (fig 2), it is represented as G. The Posterior calcaneal angle or FowlerPhilip angle is subtended by a line drawn $A B$ parallel to upper posterior aspect of calcaneus and the support surface of line CD (fig 3), It is represented as $x$. The Calcaneal pitch angle is an angle formed by line $\mathrm{CD}$ tangent to the plantar surface of the calcaneus uniting it with the horizontal sesamoid (fig 3), It is represented as $y$. The total Calcaneal angle is the sum of the Fowler-Philip angle and the Calcaneal pitch angle. It is represented as $z=x+y$ (fig 3). The data were analyzed with Excel statistical tool. The results obtained were presented in mean, standard error, and standard deviation. The z-test of 0.05 significant level was used to compare the mean for the males and females. 
RESULTS

TABLE 1: Descriptive Statistics for the Measured Angles of the Calcaneus in All Subjects.

\begin{tabular}{lccccccc}
\hline Parameters & N & Mean & SEM & SD & Var & Min & Max \\
\hline Calcaneal Pitch Angle & 302 & 14.50 & 0.20 & 3.55 & 12.66 & 10 & 30 \\
Gissane's Angle & 302 & 116.77 & 0.46 & 8.03 & 64.50 & 100 & 140 \\
Fowler-Philip's Angle & 302 & 73.50 & 0.25 & 4.32 & 18.66 & 60 & 85 \\
& & & & & & & \\
& & & & & & & \\
Total Calcaneal Angle & 302 & 88.01 & 0.24 & 4.23 & 17.91 & 73 & 101
\end{tabular}

The total population mean for the Gissane angle was $116.53 \pm 8.03$, and it ranged from $100-140^{\circ}$. The total population mean for the fowler - Philip angle was $73.50 \pm 4.32$ and it ranged from $60-$ $85^{\circ}$. The total population mean for the Calcaneal Pitch angle was $14.50 \pm 3.55$ and it ranged from $10-30^{\circ}$. The total population mean was $88.00 \pm$ 2.60 and it ranged from $73-101^{\circ}$

TABLE 2: Descriptive Statistics \& Mean Comparison of Axial Angles of the Calcaneus Based on Gender

\begin{tabular}{|c|c|c|c|c|c|c|c|c|c|}
\hline Parameters & $\mathbf{N}$ & Sex & Mean & SEM & SD & Var & $\begin{array}{l}\text { Cal. Z } \\
\text { Score }\end{array}$ & $\begin{array}{l}\text { Crit. } Z \text { score at } \\
0.05 \text { conf. level }\end{array}$ & Inference \\
\hline \multirow{3}{*}{$\begin{array}{l}\text { Calcaneal } \\
\text { Angle }\end{array}$} & 150 & $\mathrm{~F}$ & 29.95 & 0.41 & 5.05 & 25.51 & \multirow{3}{*}{0.45} & \multirow[b]{2}{*}{1.96} & \\
\hline & 152 & M & 14.41 & 0.29 & 3.55 & 12.75 & & & $\begin{array}{l}\text { There is no significant } \\
\text { difference }(p>0.05)\end{array}$ \\
\hline & 150 & $\mathrm{~F}$ & 14.41 & 0.29 & 3.57 & 12.79 & & & \\
\hline \multirow[t]{2}{*}{ Gissane's Angle } & 152 & M & 116.30 & 0.67 & 8.29 & 68.75 & \multirow[t]{2}{*}{0.52} & 1.96 & $\begin{array}{l}\text { There is no significant } \\
\text { difference }(p>0.05)\end{array}$ \\
\hline & 150 & $\mathrm{~F}$ & 116.77 & 0.64 & 7.78 & 60.55 & & & \\
\hline \multirow[t]{2}{*}{$\begin{array}{l}\text { Fowler-Philip's } \\
\text { Angle }\end{array}$} & 152 & M & 73.39 & 0.36 & 4.40 & 19.37 & \multirow[t]{2}{*}{0.47} & 1.96 & $\begin{array}{l}\text { There is no significant } \\
\text { difference }(p>0.05)\end{array}$ \\
\hline & 150 & $\mathrm{~F}$ & 73.62 & 0.35 & 4.25 & 18.05 & & \multirow[b]{2}{*}{1.96} & \\
\hline \multirow[t]{2}{*}{$\begin{array}{l}\text { Total } \\
\text { Angle }\end{array}$} & 152 & M & 88.00 & 0.38 & 4.62 & 21.40 & \multirow[t]{2}{*}{0.10} & & $\begin{array}{l}\text { There is no significant } \\
\text { difference }(p>0.05)\end{array}$ \\
\hline & 150 & $\mathrm{~F}$ & 88.03 & 0.31 & 3.80 & 14.50 & & & \\
\hline
\end{tabular}

The mean male gissane angle was $116.29 \pm 8.29$ while that of the female was $116.77 \pm 7.78$. There was no statically significant different between the Sexes ( $>>0.05)$. The mean male fowler- Philip angle was $73.38 \pm 4.40$ and $73.62 \pm 4.24$ for the female. The difference was not statically significant $(p>0.05)$. The mean male Calcaneal pitch angle was $14.59 \pm 3.54$ while that of the female was $14.41 \pm 3.57$. No statistical significant difference between the sexes( $p>0.05)$. The mean male total calcaneal angle was $87.90 \pm 3.01$ and $88.10 \pm 2.10$ for the female. There was statistically no significant difference between the sexes $(\mathrm{p}>0.05)$.

\section{DISCUSSION}

From this study, the mean value of Gissane angle for males was $116.29 \pm 8.29$ while that of females was $116.77 \pm 7.78$. There was no significant statistical differences between the sexes ( $p>0.05)$. This was also observed by studies done Turkey ${ }^{(6)}$. The total population mean was $116.53 \pm 8.03$ with a range of $100-140$. This study shows a considerable wide range for the Gissane angle in the Nigeria population as reported in previous studies in other populations as follows; In the Saudi population the Gissane angle range was 96 $152^{\mathrm{O}(11)}$. A range of $100-133^{\mathrm{O}}$ was evaluated 
for the Turkish population ${ }^{(6)}$. The Gissane angle generally decreases during calcaneal fracture. Hence the lower limit of 100 degrees for the Nigerian population, which is greater than that of the Saudi population, but the same with the Turkish population, is of interest. From this research, the fowler Philip angle for the male was $73.38 \pm 4.40$ and $73.62+4.24$ for the female. There was no significant statistical differences between the sexes $(\mathrm{p}>0.05)$. The total population mean was $73.50 \pm 4.32$ with a range of $60-85^{\circ}$. This is in agreement with studies done in Hong Kong ${ }^{(16)}$. The fowler - Philip angle from this study in the Nigerian population has a range of $60-85^{0}$ which is different from the range of $44-69^{\circ}$ in the published data, this is significant, although the literature considers as normal a fowler Philip angle of not more than $75^{\circ}$. The Hong kong population range was $46-71^{\circ}{ }^{(16)}$. This is an indication of regional variation of calcaneal parameters, which could be either due to hereditary or environmental factors or both. Hence, it is evident that a separate reference range value is required for the Nigerian population. From this research, the mean values for the calcaneal pitch angle for males were $14.59 \pm 3.54$ while that of the female was $14.41 \pm 3.57$. There was no statistical significant difference between the sexes ( $p>0.05)$, this is in agreement with studies done in Hong Kong. The total population mean was $14.50 \pm 3.55$ with a range of $10-30^{\circ}$ this corresponds to previous findings. From the literature, reference values of $15-20^{\circ}$ is considered normal ${ }^{(19,20)}$ as well as a range of 10$30^{\circ}$. In the Saudi population, a range of $20-30^{\mathrm{O}}$ were considered normal ${ }^{(21)}$. A range of $12-28^{\circ}$ for the Hong kong population were considered normal (16). The average calcaneal pitch angle in this study of $14.50 \pm 3.55$ with a range of $10-30^{\circ}$ for the Nigerian population is significant when compared with the published data. From this research, the mean values for the total calcaneal angle of males was $87.90 \pm 3.01$ and that of the female was 88.10 \pm 2.10 . There was no statistically significant difference between the sexes $(p>0.05)$, this is in agreement with studies done in Hong Kong ${ }^{(16)}$. The total population mean was $88.00 \pm 2.60$ with a range of the $73-101^{\mathrm{O}}$. A wide range as observed in this study is also in line with the findings of Sharma et al ${ }^{(16)}$.

\section{CONCLUSION}

Calcaneal angles/parameters like the Gissane angle, fowler Philip angle, calcaneal pitch angle and the total calcaneal angle have a wide range of normal limits and distribution in different populations. This study has shown the range of values for these calcaneal parameters for the Nigerian population as compared with other populations and published data. It is important to establish a normal range in a given population so as not to have a high percentage of false positive abnormal cases of calcaneal fracture. These normal range of calcaneal parameters will aid in assessing, diagnosing and reduction of calcaneal fracture.

\section{REFERENCES}

1. Igbigbi, P.S; Msamati, B. C; Matanje, B. Normal axial angles of the knee joint in adult indigenous Malawians. East Africa med Journal. 2003; 80(8): 415-418

2. Udoaka, A.I; Didia, B.C. The Calcaneal Bohler's Angle in Nigerians: A Radiologic Study. Journal of Meds and Tech. 2013; 2:81-83

3. Platzer, Werner. Color Atlas of Human Anatomy. (5th ed.). $2004 ; 1$

4. Pearlman, P; Dubois, P; Siskind, V. Validating the process of taking lateral foot X-rays. JAPMA. 1996; 86:317

5. Malgaigne, J.F. Double vertical fractures of the pelvis. ClinOrthopRelat Res. 2007; 458:17-19.

6. Seyahi, A; Uludaq, S; Koyuncu, L.O; Atalar, A.C; Demirhan, N. The Calcaneal angles in the Turkish population. Acta.Orthop.Traumatol.Turc. 2009; 43(5): 406-11. 
7. Shoukry, F.A; Aref, Y.K; Sabry, A.A. Evaluation of the normal calcaneal angles in Egyptian population. 2012; 48:91-7.

8. Igbigbi, P.S; Mutesaria AN. Calcaneal angles in Ugandans. ClinAnat. 2003; 16:328-30

9. Keener, B.J; Sizensky, J.A. The anatomy of the calcaneus and surrounding structures. Foot Ankle Clin. 2005; 10:413-424.

10. Gissane, W. Proceedings of the British Orthopedic Association. Journal of Bone Joint SurgAm. 1947; 29:254-255.

11. Khoshhai, K.L; Ibrahim, A.F; AlNakshabandi, N.A; Zamzam, M.M; AlBoukai, A.A. Bohler's and Gissane's angles of the calcaneus in the Saudi population. Saudi Med. Journal 2004; 25(12): 1967-70.

12. Stephens M. Haglund's deformity and retrocalcaneal bursitis. OrthopClin North Am. 1994; 25:41.

13. Coughlin, M; Kaz, A. Correlation of Harris Mats, physical exam, Pictures, and radiographic measurements in adult flatfoot deformity. Foot Ankle Int. 2009; 30: 604 .

14. Heneghan, M; Wallace, T. Heel pain due to retrocalcaneal bursitis. JAPMA. 2013; 34: 103

15. Fowler A, Philip JF. Abnormality of the Calcaneus as a cause of painful heel. Br Jsurg. 1945; 32:494-498

16. Sharma SC, Singh R, Piplani H, Sharma A. Radiological evaluation and role of surgery in retrocalcaneal bursitis. Hongkong J Orthop Surg. 2005; 9: 8-15

17. Vanderwilde, R; Staheli, L.T; Chew, D.E; Malagon, V. Measurements on radiographs of the foot in normal infants and children. JournalBone Joint Surg Am. 1988; 70:407-15.

18. Chen, C.H; Huang, M.H; Chen, T.W; Weng, M.C; Lee, C.L; Wang, G.J . The correlation between selected measurements from footprint and radiograph of flatfoot. Arch Phys Med Rehabil. 2006; 87:235-240.

19. Younger, A.S; Sawatzky, B; Dryden, P. Radiographic assessment of adult flatfoot. Foot Ankle Int. 2005; 26:820-825.

20. Castro-Aragon, O; Vallurupalli, S; Warner, M. Ethnic radiographic foot differences. Foot Ankle Int. 2009 30:57.

21. Prichasuk, S. The relationship of pesplanus and calcaneal spur to planter heel pain. ClinOrthop. 1994; 306: 192-196.

22. Chauveaux, D; Liet, p; Lehuec, J.C A new radiologic measurement for the diagnosis of haglund's deformity. SurgRadiolAnat. 1991; 13:39. 